\title{
Simultaneous early adenocarcinoma and mucosa-associated lymphoid tissue (MALT) lymphoma of the stomach associated with Helicobacter pylori infection
}

\author{
Takehiro Sakai ${ }^{1}$, Yuta Ogura ${ }^{1}$, Junichi Narita ${ }^{1}$, Takemichi Suto ${ }^{2}$, Daisuke Kimura ${ }^{2}$, Susumu Ainai $^{1}$, \\ Hajime Fujita ${ }^{1}$, and Mitsuru Kamada ${ }^{3}$ \\ ${ }^{1}$ The Department of Surgery, Aomori Rosai Hospital, 1 Minamigaoka, Shirogane-cho, Hachinohe 031-8551, Japan \\ ${ }^{2}$ The First Department of Surgery, Hirosaki University School of Medicine, Hirosaki, Japan \\ ${ }^{3}$ The Department of Pathology, Aomori Rosai Hospital, Hachinohe, Japan
}

\begin{abstract}
The simultaneous association of gastric carcinoma with gastric lymphoma is a rare event. Recent studies have suggested that not only gastric cancer but also primary gastric lymphomas, especially those of mucosa-associated lymphoid tissue (MALT) type, are associated with Helicobacter pylori infection. We report on a 51-year-old woman who was referred to our hospital for the evaluation of abnormal shadows revealed by an upper gastrointestinal radiography series. Endoscopy of the upper gastrointestinal tract revealed early cancer in the middle body of the stomach. Biopsy of the lesion subsequently proved it to be a signet-ring cell carcinoma. Total gastrectomy was performed, under a diagnosis of early gastric carcinoma. The resected specimen revealed two grossly separate lesions. Histological examination confirmed that the gastric body lesion was compatible with early moderately differentiated tubular adenocarcinoma of type 0-IIc, while the lesion of the fundus corresponded to MALT lymphoma. $H$. pylori was detected, and chronic gastritis was also present in the resected gastric specimen. $H$. pylori infection may have played a major role in the development of both the MALT lymphoma and the adenocarcinoma of the stomach in this patient.
\end{abstract}

Key words MALT lymphoma · Adenocarcinoma - Coexistence $\cdot$ Helicobacter pylori infection $\cdot$ Stomach

\section{Introduction}

Gastric cancer is one of the most common malignancies, whereas primary gastric lymphoma is relatively uncommon, accounting for only $1 \%-7 \%$ of all malignant neoplasms of the stomach [1]. The occurrence of both malignant gastric lymphoma and gastric cancer in the

Offprint requests to: T. Sakai

Received: February 4, 2003 / Accepted: April 23, 2003 same patient is rare, and little is known regarding the clinicopathologic characteristics of such cases.

Helicobacter pylori is believed to play a causative role in chronic active gastritis, peptic ulcer, and gastric cancer. Recent studies have suggested that not only gastric cancer but also primary gastric lymphomas, especially those of mucosa-associated lymphoid tissue (MALT) type, are associated with $H$. pylori infection $[2,3]$.

We report herein a rare case of the simultaneous occurrence of early gastric cancer and MALT lymphoma with $H$. pylori infection.

\section{Case report}

On July 4, 2001, a 51-year-old woman was referred to our hospital for the evaluation of abnormal shadows revealed by an upper gastrointestinal radiography series taken at an annual general health examination at a local hospital on June 26, 2001. On physical examination the patient was in good general condition and well nourished (height, $161 \mathrm{~cm}$; weight, $71 \mathrm{~kg}$ ). No nodes were palpable. Abdominal examination showed a right lower abdominal oblique surgical scar from a previous appendectomy. There was no abdominal tenderness or mass. The liver and spleen were not palpable.

Results of laboratory studies, including blood cell counts and differentials, liver function tests, renal function tests, and urinalysis, were within normal ranges. Results for serological measurements of carcinoembryonic antigen (patient, $1.3 \mathrm{ng} / \mathrm{ml}$; normal, less than $5 \mathrm{mg} / \mathrm{ml}$ ) and carbohydrate antigen (CA) 19-9 (patient, $9.4 \mathrm{ng} / \mathrm{ml}$; normal, less than $37 \mathrm{ng} / \mathrm{ml}$ ) were unremarkable.

Endoscopy of the upper gastrointestinal tract revealed a shallow depressed lesion with converging folds in the posterior wall of the gastric body (Fig. 1A). Biopsy of the lesion subsequently proved it to be a signet-ring cell carcinoma. Abdominal echography 

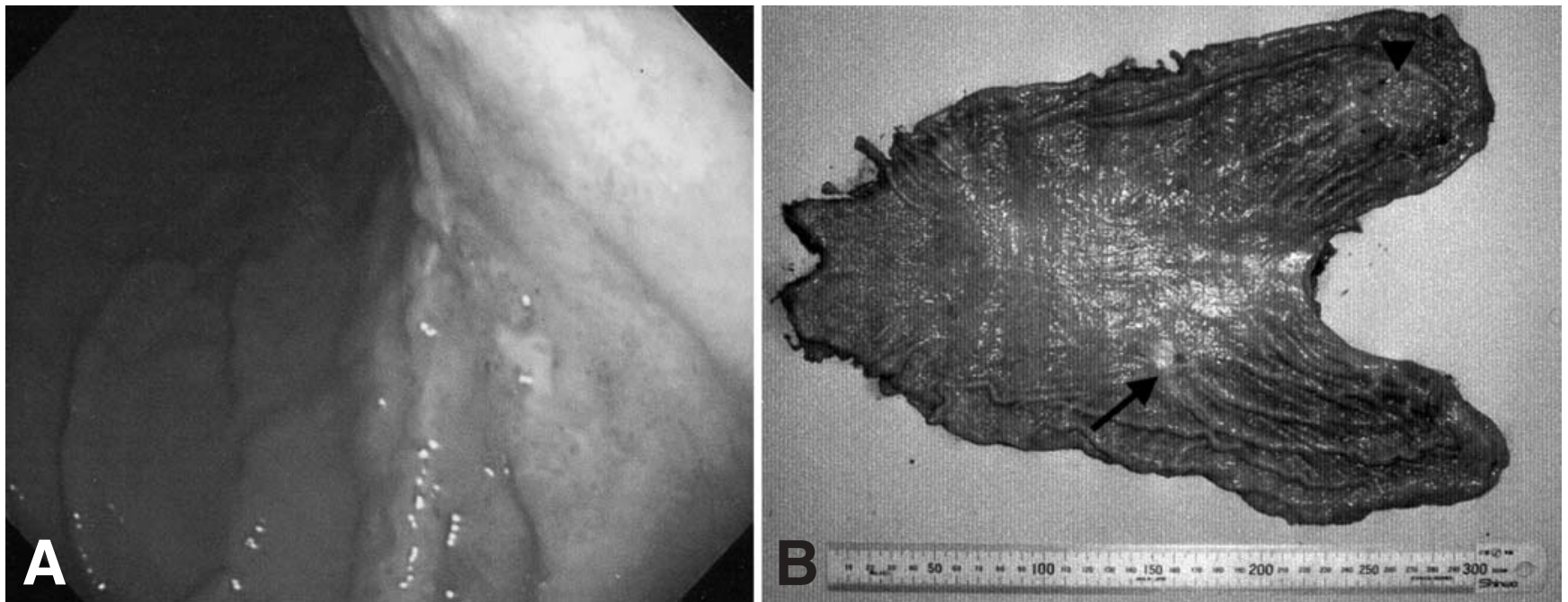

Fig. 1. A Endoscopic image shows an irregularly shaped depressed lesion with converging mucosal folds broken at the margin of the lesion in the posterior wall of the gastric body. The endoscopic diagnosis was type IIc early gastric carcinoma. B The resected specimen reveals a type IIc early carcinoma, measuring $2.8 \times 2.0 \mathrm{~cm}$, in the posterior wall of the gastric body (lower arrow), and a small depressed lesion in the anterior wall of the gastric fundus (arrowhead)

and computed tomography (CT) revealed fatty liver, but there was no evidence of liver metastasis or lymphadenopathy.

Therefore, total gastrectomy and regional lymphadenectomy was performed, on September 2, 2002, under a diagnosis of early gastric cancer. The postoperative course was uneventful.

Macroscopically, the resected specimen revealed two grossly separate lesions (Fig. 1B). In the posterior wall of the gastric body, a type IIc early carcinoma, measuring $2.8 \times 2.0 \mathrm{~cm}$, was observed. There was also a small depressed lesion, measuring $1.5 \mathrm{~cm}$, in the anterior wall of the gastric fundus.

On microscopic examination, the coexistence of adenocarcinoma and MALT lymphoma was clearly observed. The gastric body lesion was early moderately differentiated tubular adenocarcinoma of type 0-IIc, according to the classification of the Japan Gastroenterological Endoscopy Society (Fig. 2A). No nodal involvement by carcinoma was observed. The lesion in the fundus was a MALT-type lymphoma (Fig. 2B,C,D). Small- to medium-sized centrocyte-like cells had infiltrated the muscularis propria and some glands (lymphoepithelial lesions). The monoclonality of the lymphoma was evaluated with a T-cell (UCHL 1) marker and a B-cell (L26) marker. The lymphoma cells were stained by L26 but not by UCHL 1, confirming that it was a B-cell lymphoma. The surrounding nonneoplastic mucosa exhibited chronic gastritis with severe lymphocyte infiltration (Fig. 2E). H. pylori organisms were detected by Gimenez staining (Fig. 2F). Thus, a final pathological diagnosis of synchronous
MALT lymphoma and adenocarcinoma was established.

\section{Discussion}

Adenocarcinoma is the most common of the tumors arising in the stomach, accounting for approximately $95 \%$ of gastric neoplasms. The majority of the remaining tumors are lymphomas, while mesenchymal tumors are rare [1]. Mucosa-associated lymphoid tissue (MALT) lymphoma is a low-grade primary B-cell lymphoma. It is characterized by prominent and often multifocal lymphoepithelial lesions with dense, diffuse infiltrates of centrocyte-like cells within the lamina propria $[4,5]$.

The simultaneous association of gastric carcinoma with gastric lymphoma is a rare event. Ishihama et al. [6] reviewed the findings for 66 patients with gastric malignant lymphoma and coexisting gastric adenocarcinoma reported in the Japanese-language literature from 1962 to 1994. Non-Hodgkin's lymphoma arising from MALT is a special type of extranodal marginal-zone lymphoma. The concept of MALT lymphoma was first established by Isaacson and Wright [7] in 1983. As it is now accepted that the majority of lesions previously diagnosed as pseudolymphomas are actually low-grade B-cell lymphomas of MALT type, it is probable that these represent further cases of combined gastric lymphoma-adenocarcinoma [8]. To the best of our knowledge, only 12 Japanese patients with synchronous occurrence of gastric adenocarcinoma and gastric 

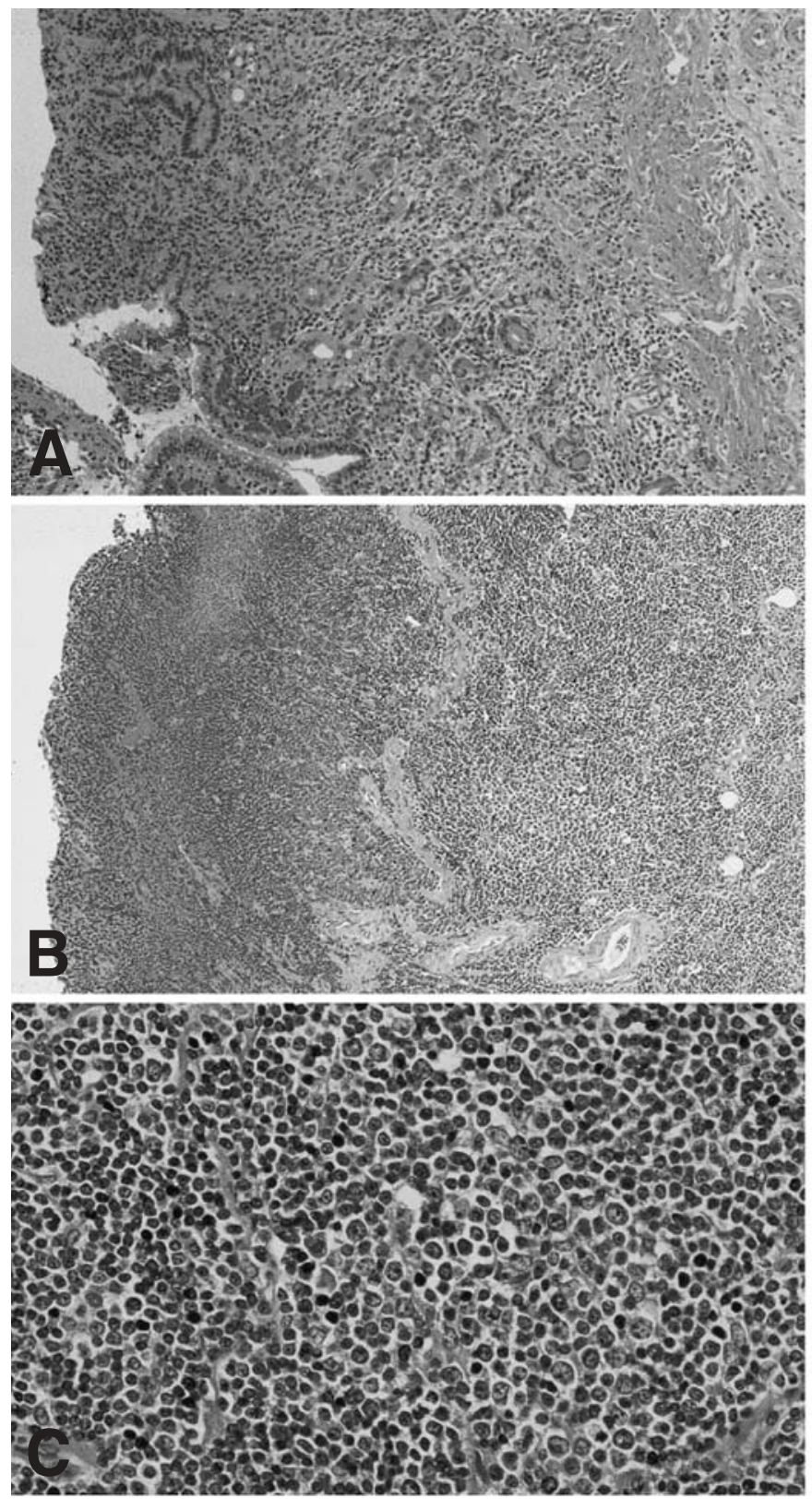

Fig. 2. A Histological findings of the resected specimen from the type IIc early gastric carcinoma revealed moderately differentiated tubular adenocarcinoma, limited to the mucosa. B The small depressed lesion in the anterior wall of the gastric fundus revealed mucosa-associated lymphoid tissue (MALT) lymphoma. C Small- to-medium-sized centrocyte-like cells infiltrated the muscularis propria and some glands. D Some

MALT lymphoma have been previously reported in the English- or Japanese-language literature [9-14].

Including our present patient, we reviewed the clinicopathological features of these 13 patients in Japan (Table 1). The patients ranged in age from 27 to 79 years (mean, 57.7 years), and showed male predominance, with 8 men and 5 women. Six of the 13 lympho-
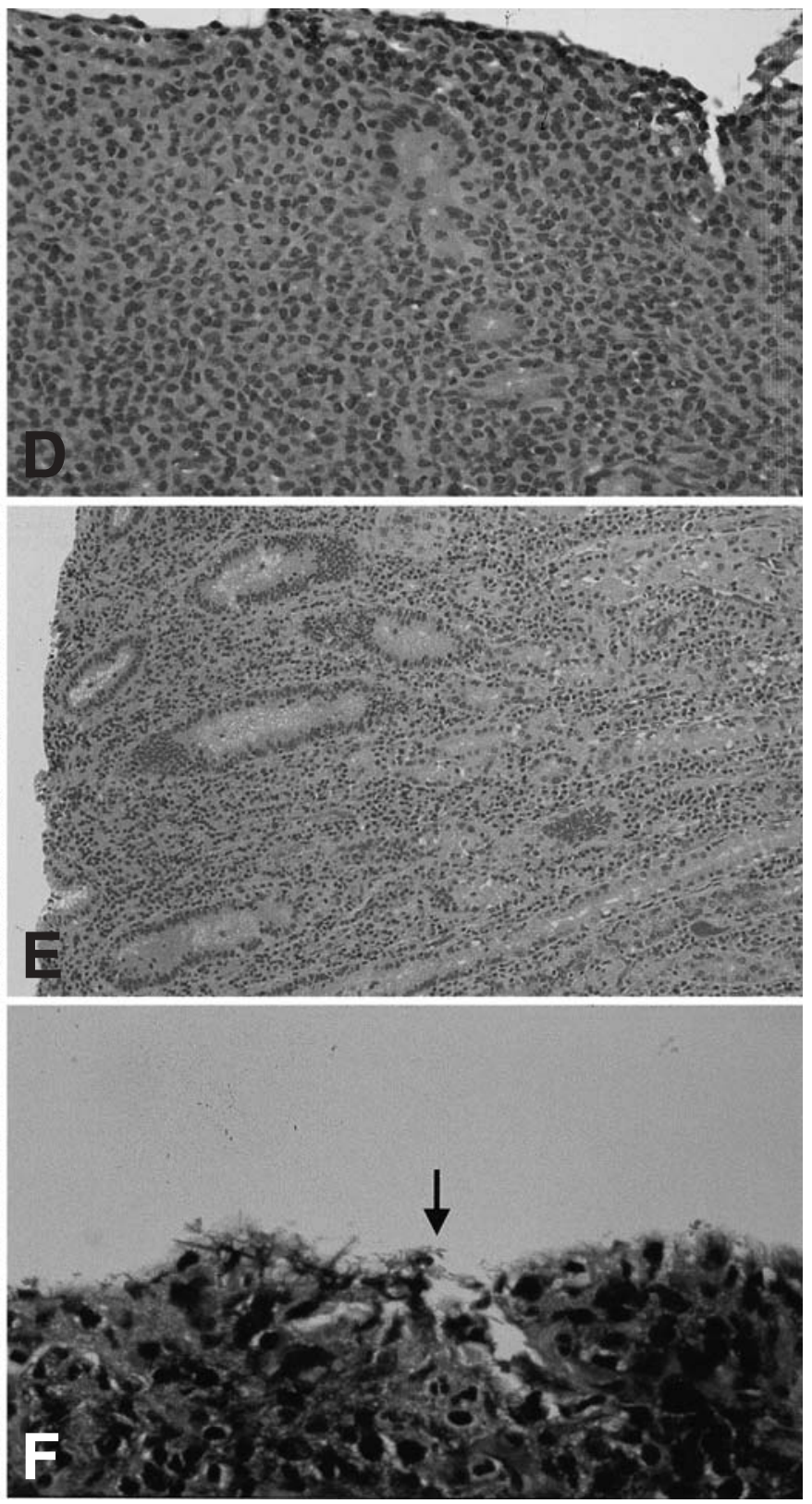

lymphoma cells had invaded the gastric glands to form a lymphoepithelial lesion. E The surrounding nonneoplastic mucosa exhibited chronic gastritis with severe lymphocyte infiltration. F Helicobacter pylori organisms were detected by Gimenez staining (arrow). A H\&E, $\times 33$; B H\&E, $\times 25$; C $\mathrm{H} \& \mathrm{E}, \times 100 ; \mathbf{D} \mathrm{H} \& \mathrm{E}, \times 100 ; \mathbf{E} \mathrm{H} \& \mathrm{E}, \times 40 ; \mathbf{F} \times 160$

mas $(46 \%)$ were mainly located in the upper third of the stomach, whereas 12 of the 13 adenocarcinomas $(92 \%)$ were found in the distal two-thirds of the stomach. The most common macroscopic appearance of adenocarcinoma was type IIc (6 cases), followed by type IIa (4 cases). The degree of lymphomatous invasion was as follows: 7 lymphomas massively invaded the deep por- 
Table 1. Clinocopathological features of 13 patients with synchronous adenocarcinoma and MALT lymphoma of the stomach

\begin{tabular}{|c|c|c|c|c|c|c|c|c|c|c|c|c|c|}
\hline \multirow{3}{*}{$\begin{array}{l}\text { Case. } \\
\text { no }\end{array}$} & \multirow[b]{3}{*}{ Author } & \multirow{3}{*}{$\begin{array}{c}\text { Age } \\
\text { (years) }\end{array}$} & \multirow[b]{3}{*}{ Sex } & \multicolumn{4}{|c|}{ Adenocarcinoma } & \multirow{2}{*}{\multicolumn{2}{|c|}{ Lymphoma }} & \multirow[b]{3}{*}{ Node } & \multirow{3}{*}{$\begin{array}{c}\text { Helicobacter } \\
\text { pylori }\end{array}$} & \multirow[b]{3}{*}{ Gastritis } & \multirow{3}{*}{$\begin{array}{l}\text { Co./ } \\
\text { Sep. }\end{array}$} \\
\hline & & & & & \multirow{2}{*}{$\begin{array}{c}\text { Macro } \\
\text { type }\end{array}$} & \multirow{2}{*}{$\begin{array}{l}\text { Micro } \\
\text { type }\end{array}$} & \multirow[b]{2}{*}{ Depth } & & & & & & \\
\hline & & & & Site & & & & Site & Depth & & & & \\
\hline 1 & Nakamura [1] & 27 & M & $\mathrm{L}$ & IIa & Int & $\mathrm{m}$ & M & $\mathrm{mp}$ & Ly & + & & Sep \\
\hline 2 & Nakamura [1] & 38 & M & $\mathrm{Mi}$ & IIc & Dif & $\mathrm{sm}$ & M & $\mathrm{sm}$ & - & + & & Sep \\
\hline 3 & Nakamura [1] & 70 & M & $\mathrm{L}$ & IIc & Int & $\mathrm{m}$ & M & $\mathrm{mp}$ & - & + & & Sep \\
\hline 4 & Nakamura [1] & 72 & M & $\mathrm{L}$ & 2 & Int & se & $\mathrm{U}$ & se & $\mathrm{ACa}$ & + & & Sep \\
\hline 5 & Nakamura [1] & 75 & $\mathrm{~F}$ & $\mathrm{~L}$ & IIa & Int & $\mathrm{m}$ & $\mathrm{U}$ & $\mathrm{sm}$ & - & + & & Sep \\
\hline 6 & Nakamura [1] & 53 & M & $\mathrm{Mi}$ & IIc & Int & $\mathrm{sm}$ & $\mathrm{U}$ & $\mathrm{sm}$ & - & + & & Co \\
\hline 7 & Nakamura [1] & 67 & $\mathrm{~F}$ & $\mathrm{Mi}$ & IIa & Int & $\mathrm{sm}$ & $\mathrm{U}$ & $\mathrm{sm}$ & - & + & & $\mathrm{Co}$ \\
\hline 8 & Kanamoto [10] & 47 & M & $\mathrm{L}$ & IIc & Dif & $\mathrm{m}$ & $\mathrm{L}$ & $\mathrm{sm}$ & & + & + & $\mathrm{Co}$ \\
\hline 9 & Kajimura [11] & 72 & $\mathrm{~F}$ & $\mathrm{~L}$ & IIc & Int & $\mathrm{m}$ & M & - & - & + & + & Sep \\
\hline 10 & Takahashi [12] & 37 & M & $\mathrm{Mi}$ & $\mathrm{IIb}$ & Int & $\mathrm{m}$ & ML & $\mathrm{sm}$ & - & + & + & Co \\
\hline 11 & Mochizuki [13] & 62 & M & $\mathrm{Mi}$ & 3 & Dif & se & $\mathrm{L}$ & $\mathrm{sm}$ & $\mathrm{ACa}$ & + & & Sep \\
\hline 12 & Sakatoku [14] & 79 & $\mathrm{~F}$ & $\mathrm{U}$ & $\mathrm{I}$ & Int & $\mathrm{sm}$ & $\bar{U}$ & - & - & + & & Sep \\
\hline 13 & Our patient & 51 & $\mathrm{~F}$ & $\mathrm{Mi}$ & IIc & Int & $\mathrm{m}$ & $\mathrm{U}$ & $\mathrm{mp}$ & - & + & + & Sep \\
\hline
\end{tabular}

MALT, mucosa-associated lymphoid tissue; U, upper third; Mi, middle third; L, lower third; Int, intestinal; Dif, diffuse; m, mucosa; sm, submucosa; mp, muscularis propria; se, serosa; Ly, lymphoma; ACa, adenocarcinoma; Co, collision; Sep, separate

tion of the submucosa, 3 involved the muscularis propria, 1 involved all layers of the gastric wall, and findings for 2 were unknown. In contrast, 11 of the 13 adenocarcinomas $(85 \%)$ were early adenocarcinomas restricted to the mucosa and submucosa. Ten adenocarcinomas were well-to-moderately differentiated adenocarcinomas of the intestinal type, whereas the other 3 were poorly differentiated adenocarcinomas of the diffuse type. Regional node involvement was found in 2 advanced adenocarcinomas. $H$. pylori was detected in all 13 patients.

Because of the rare occurrence of simultaneous primary gastric lymphoma and gastric carcinoma, this occurrence was previously considered to reflect a mere coincidence, rather than a direct relationship. At present, however, carcinoma and lymphoma of the stomach are both considered to be related to H. pylori infection [2,3]. H. pylori has been found in a mean of about $50 \%$ of patients with gastric cancer and in about $90 \%$ of patients with MALT-type gastric lymphoma $[4,15,16]$. The possible coexistence of both primary gastric lymphoma and carcinoma should be kept in mind, especially in patients with $H$. pylori, because different etiopathogenetic roles for $H$. pylori have been postulated for these two diseases. H. pylori plays a key role in the natural history of gastric MALT lymphoma, representing an example of antigen-mediated tissue stimulation and lymphoproliferation, with possible subsequent lymphomagenesis [4,17]. Furthermore, anti-H. pylori treatment has been demonstrated to be effective in curing early-stage low-grade lymphoma [18]. Lymphoid follicles are not present in the normal stomach, but develop in the setting of chronic gastritis. Genta and Hamner [19] have shown a strong correlation between follicular gastritis and $H$. pylori infection. On the other hand, infection has been linked to the intestinal type of gastric adenocarcinoma through a chain of events that starts as acute gastritis and progresses to chronic gastritis, atrophic gastritis, intestinal metaplasia, dysplasia, and, eventually, adenocarcinoma formation [20]. In our present patient, $H$. pylori infection may have played a major role in the development of both the MALT lymphoma and the adenocarcinoma of the stomach. Severe infiltration of lymphocytes into the mucosa was also present in the background mucosa of gastric adenocarcinoma, showing the findings of chronic active gastritis. Furthermore, small- to medium-sized lymphocytes had infiltrated the muscularis propria in the lymphomatous lesion. The common finding in the background of the carcinomatous and lymphomatous lesions was severe infiltration of lymphocytes. The synchronous occurrence of gastric adenocarcinoma and MALT lymphoma in patients with chronic gastritis adds evidence to the theory that $H$. pylori infection plays an early role in the generation of both types of neoplasms. H. pylori infection could be one of the common etiologies in gastric adenocarcinoma and gastric MALT lymphoma. However, apart from epidemiological evidence, the role of $H$. pylori in the generation of gastric adenocarcinoma and gastric MALT lymphoma is still unclear.

It may be difficult to diagnose the two different tumors before surgery. In our present patient, the carcinoma was recognized on endoscopy as an irregularly shaped depressed lesion accompanied by definite disruption of the converging mucosal folds at the margin, whereas the lymphoma was not detected before surgery. Because most patients with gastric adenocarcinoma and coexisting gastric MALT lymphoma, particu- 
larly in Japan, have associated $H$. pylori infection, the presence of MALT gastric lymphoma should be taken into consideration when gastric adenocarcinoma with gastritis is detected on endoscopy. H. pylori may be investigated histopathologically and/or serologically in patients with gastric adenocarcinoma; then, endoscopic reexamination may be considered when $H$. pylori infection is identified. In surgical specimens, not only the lesions of adenocarcinoma but also the background mucosa of cancerous lesions must be examined in regard to the infiltration of lymphocytes, and the presence of gastritis, as well as the presence of $H$. pylori. Considering the occurrence of both gastric adenocarcinoma and gastric lymphoma, endoscopic follow-up should be performed in the remnant stomach when $H$. pylori infection is present.

The prognosis of patients with double gastric lymphoma and adenocarcinoma has yet to be clarified, due to the lack of any longterm follow-up observations. The follow-up study conducted by Nakamura et al. [1] revealed that the survival probability for patients with double primary gastric lymphoma and adenocarcinoma appeared to be similar to that for patients with gastric adenocarcinoma without MALT lymphoma.

The treatment of gastric MALT lymphoma includes surgery, radiation therapy, and chemotherapy. Because gastric MALT lymphomas have a high association with $H$. pylori infection, eradication of $H$. pylori with antibiotics is very important $[2,4,18]$. There are recent reports of the regression of low-grade MALT lymphoma at shortterm follow-up after the medical eradication of $H$. pylori. Hence, antibiotic therapy has been proposed prior to surgery in patients with low-grade gastric MALT lymphomas [18]. Because the longterm cure rate of MALT lymphoma after antibiotic therapy is unknown, patients still require periodic surveillance endoscopies and may require more traditional treatment of their lymphoma. Antibiotic therapy may fail to cure gastric lymphomas when there is a bulky tumor with a high-grade component or when the gastric lymphoma is associated with carcinoma [21].

Clear guidelines for management have not yet been designed for synchronous adenocarcinoma and MALT lymphoma of the stomach, as the condition is relatively rare, and newly accepted. In this situation, the coexisting adenocarcinoma must be diagnosed correctly and resected surgically, because chemotherapy is not effective for this carcinoma. In Japan, total gastrectomy has been routinely performed. Although a total gastrectomy was performed in our patient for the treatment of gastric cancer, a combination of a partial gastrectomy and antibiotic therapy might be an alternative choice for the treatment of these double malignancies, because recent reports have suggested that low-grade MALT lymphomas may regress after the eradication of $H$. pylori [11-13]. However, in patients treated with the combination of a partial gastrectomy and H. pylori eradication therapy, periodic surveillance endoscopies are required, because it remains unclear whether the neoplastic clone is eliminated or merely suppressed. Surgery should be considered in patients with highgrade lymphoma or in those who are resistant to the eradication therapy.

\section{References}

1. Nakamura S, Akazawa K, Yao T, Tsuneyoshi M. Primary gastric lymphoma: a clinicopathological study of 233 cases with special reference to evaluation with MIB-1 index. Cancer 1995;76:131324.

2. Parsonnet J, Hansen S, Rodriguez L, Gelb AB, Warnke RA, Jellum E, et al. H. pylori infection and gastric lymphoma. N Engl J Med 1994;330:1267-71.

3. Parsonnet J, Friedman GD, Vandersteen DP, Chang Y, Vogelman JH, Sibley RK. H. pylori infection and risk of gastric carcinoma. N Engl J Med 1991;325:1127-31.

4. Wotherspoon AC, Ortiz-Hidalgo C, Falzon MF, Isaacson PG. Helicobacter pylori-associated gastritis and primary B-cell gastric lymphoma. Lancet 1991;338:1175-6.

5. Wotherspoon AC, Doglioni C, Isaacson PG. Low-grade gastric Bcell lymphoma of mucosa-associated lymphoid tissue (MALT): a multifocal disease. Histopathology 1992;20:29-34.

6. Ishihama T, Kondo H, Saito D, Yamaguchi H, Shirao K, Yokota $\mathrm{T}$, et al. Clinocopathological studies on coexisting gastric malignant lymphoma and gastric adenocarcinoma: report of four cases and review of the Japanese literature. Jpn J Clin Oncol 1997; 27:101-6.

7. Isaacson $\mathrm{P}$, Wright $\mathrm{DH}$. Malignant lymphoma of mucosaassociated lymphoid tissue. Cancer 1983;52:1410-6.

8. Goteri G, Ranaldi R, Rezai B, Baccarini MG, Beazi I. Synchronous mucosa-associated lymphoid tissue lymphoma and adenocarcinoma of the stomach. Am J Surg Pathol 1997;21:505-9.

9. Nakamura S, Aoyagi K, Iwanaga S, Yao T, Tsuneyoshi M, Fujiwara M. Synchronous and metachronous primary gastric lymphoma and adenocarcinoma-a clinicopathologic study of 12 patients. Cancer 1997;79:1077-85.

10. Kanamoto K, Aoyagi K, Nakamura S, Hizawa K, Suekane H, Sakamoto K, et al. Simultaneous coexistence of early adenocarcinoma and low-grade MALT lymphoma of the stomach associated with Helicobacter pylori infection: a case report. Gastrointest Endosc 1998;47:73-5.

11. Kajimura M, Ootake M, Nakagawara M. Low grade MALToma and cancer of the stomach in a patient with Helicobacter pylori infection: a case report. Dig Endosc 1998;10:318-22.

12. Takahashi H, Tomita T, Hayakawa H. Synchronous early gastric adenocarcinoma and MALT-lymphoma with Helicobacter pylori infection. Jpn J Gastroenterol Surg 2001;34:571-5.

13. Mochizuki Y, Makino T, Yamazaki Y, Suda T, Takemura H, Nakamura N. Synchronous gastric adenocarcinoma and MALT-type lymphoma with Helicobacter pylori infection. Jpn J Gastroenterol Surg 2000;33:605-9.

14. Sakatoku M, Ietsugu K, Nakashima H, Kiyohara K, Kosugi M, Terahata S. A case of early endocrine cell carcinoma and gastric lymphoma and early gastric cancer. J Jpn Surg Assoc 2001;62: 2913-17.

15. Wotherspoon AC, Issacson PG. Synchronous adenocarcinoma and low grade B cell lymphoma of mucosa associated lymphoid tissue (MALT) of the stomach. Histopathology 1995;27:325-7.

16. Loffeld RJLF, Willems I, Flendrig JA, Arends JW. Helicobacter pylori and gastric carcinoma. Histopathology 1990;17:341-51. 
17. Issacson PG. Mucosa-associated lymphoid tissue lymphoma. Semin Hematol 1999;36:139-47.

18. Bayerdorffer E, Neubauer A, Rudolph B, Thiede C, Lehn N, Eidt $\mathrm{S}$, et al. Regression of primary gastric lymphoma of mucosa associated lymphoid tissue type after cure of Helicobacter pylori infection. Lancet 1995;345:1591-4.

19. Genta RM, Hamner HW. The significance of lymphoid follicles in the interpretation of gastric biopsies. Arch Pathol Lab Med 1994;118:740-3.
20. Correa P, Ruiz B. Helicobacter pylori and gastric cancer. In: Rathbone BJ, Heatley RV, edsitors. Helicobacter pylori and gastroduodenal diseases. 2nd Ed. Oxford: Blackwell Scientific; 1992. pp. $158-64$.

21. Pescatore $\mathrm{P}$, Heine M, Manegold BC. Cure of gastric lymphoma with antibiotics. Gastroenterology 1995;109:334-5. 